\title{
Effects of Temperature and Ambient Pressure on Spray Characteristics of Biodiesel Combustion
}

\author{
M. Jaat ${ }^{1, a}$, Amir Khalid ${ }^{1, b}$, Azwan Sapit ${ }^{1, c}$, S.M Basharie ${ }^{1, d}$, \\ Adiba Rhaodah Andsaler ${ }^{1}$, Him Ramsy ${ }^{1, \mathrm{e}}$ \\ ${ }^{1}$ Automotive Research Group (ARG), Centre for Energy and Industrial Environment Studies \\ (CEIES), Universiti Tun Hussein Onn Malaysia, Parit Raja, Batu Pahat, 86400 Johor, Malaysia \\ anorrizam@uthm.edu.my,bamirk@uthm.edu.my
}

Keywords: Diesel, Constant Chamber, Spray Area, Spray Angle

\begin{abstract}
Diesel fuel injection is the most dominant in ignition process of the diesel engines combustion. Diesel engines have been widely used in heavy-duty and light-duty vehicles due to their higher fuel economy, efficient and powerful than spark ignition (SI) engines. The principal objective of this research is to seek the effect of temperature and pressure on the spray characteristics, as well as fuel-air mixing characteristics. Experiments were performed in a constant volume chamber at specified ambient gas temperature and pressure. This research was continued with injecting diesel fuel into the chamber using a Bosch common rail system. Direct photography technique with a digital camera was used to clarify the real images of mixture formation such as spray penetration, fuel evaporation and spray interference. The liquid phase of the spray reaches a maximum penetration distance soon after the start of injection, while the vapour phase of the spray continues to penetrate downstream. The condition to which the fuel is affected was estimated by combining information on the wall chamber temperature, ambient temperature and photographs of the spray. The increases in ambient pressure inside the chamber resulting in gain of spray area and wider spray angle. Thus predominantly promotes for a better fuel-air premixing.
\end{abstract}

\section{Introduction}

Diesel engine known as a compression ignition (CI) engine that uses the heat of compression to initiate ignition to burn the fuel into the combustion machine contrast to spark ignition engines (SI). Diesel engine has the highest thermal efficiency of any regular internal or external combustion due to high compression ratio. An optically accessible, direct injection combustion system was used to investigate the effect of temperature and ambient pressure on fuel air-mixing and flame development. In this study, the parameters that will be investigated are the ambient pressure and pressure of the combustion chamber.

Many efforts have been put to meet more and more stringent new emissions regulations due to development of diesel engine while at the same time enhancing the performance of diesel engines[1].A constant volume chamber is an excellent tool to study effect of temperature on auto ignition of combustible mixtures as it gives direct measure of ignition delay[2-3]. The effects of temperature on ignition process are investigated up to the initial stages of pressure rise, which occurred as a result of net heat release due to evaporation of fuel and heating. Furthermore, based on the obtained data, a relation between temperature rises and spray formation could be observed.

In a research done by Yiming Wang., et. al.[4] on a study of the combustion phenomena under high temperature using constant volume chamber has concluded that at high temperature the ignition delay becomes very short and the ignition occurs near the nozzle tip and lastly the combustion duration was prolonged. The decrease of temperature dependence at high temperatures is due to the physical delay in the beginning of injection. Fuel quantity has no effect on ignition delay at high temperatures while the fuel quantity increases at low temperature due to endothermic effect of the spray[5]. 
The research is to investigate diesel spray characteristic under high temperature and pressure environment for constant volume chamber. In direct injection diesel engines, fuel is injected directly into the combustion chamber. Spray atomization and fuel air mixing play a role on engine performance in term of combustion and emission. The injection was performed when the desired pressure and temperature conditions were reached. A high-speed camera image was used and data is analyze before any conclusion is made and compared. Hopefully with this study, it gives a lot of help to understand and solved the problem that faced during the development process also improving the entire of combustion process.In this experiment, spray tip penetration, projected spray angle area and spray volume is measured up to certain or suitable pressure.

\section{Experimental Setup}

Figure 1 shows the experimental setup, which comprises a combustion-type constant-volume chamber, thermocouple and temperature probe. The constant volume chamber allows the same ambient conditions as in a small diesel engine cylinder. The heating system was inserted into the combustion chamber which the chamber is then connected to a compressor to be able to pressurise it. The ambient temperature can be controlled by adjusting heating system as thermocouple was screwed into the chamber to be able to measure the temperature as well as withstand the pressure of the combustion chamber.

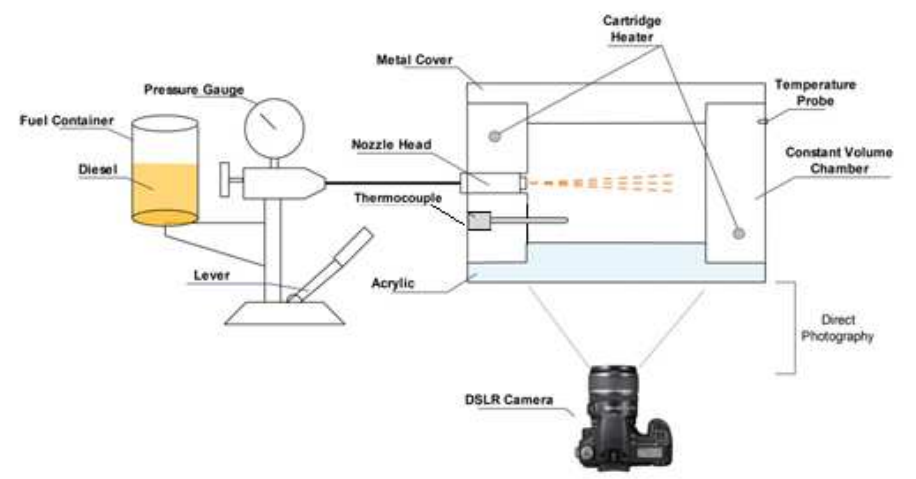

Figure 1: Schematic Diagram of Spray Pattern Experiment

The experiment was made under constant fuel injection volume. Temperature of the metal block and thermocouple was recorded under normal condition. The chamber is depressurized and the heating system was switched on. The temperature detected by the thermocouple and also the temperature probe was recorded. Pressure of the constant volume chamber was increased from 100 $\mathrm{kPa}$ up to $600 \mathrm{kPa}$ at $100 \mathrm{kPa}$ intervals and the temperature of the combustion chamber walls was set at $20,50,70$ and $85^{\circ} \mathrm{C}$ in all pressure tests conducted.

The injector nozzle head was connected to a BOSCH test rig to manually simulate the spray in the chamber. The spray patterns were captured under various parameters such as temperature and pressure. This is done to simulate the fuel injection in the combustion chamber of a small highspeed diesel engine. One of the base surfaces of the chamber was composed of pyrex glass to observe spray characteristics. Direct photography method was used to capture the image of the spray in the chamber for each of the parameters.

\section{Result and Discussion}

The data of pressure and temperature were analyzed whereas certain parameters were set to match with spray pattern and characteristic. As previous literature review discussed, spray atomization and fuel air-mixing play a significant role on engine performance, combustion and emission but here the effect of pressure to temperature was investigated.The effect offixed temperature, $\mathrm{T}_{\mathrm{c}}\left(20-85^{\circ} \mathrm{C}\right)$ on the ambient temperature is shown in Figure 2. The ambient temperature, $\mathrm{T}_{\mathrm{a}}$ is higher than block temperature, $\mathrm{T}_{\mathrm{b}}$ meanwhile a slightly increase in pressure is observed for all temperature range. For $\mathrm{Tc}=20^{\circ} \mathrm{C}, \mathrm{T}_{\mathrm{b}}$ is significantly stable and no changes can be seen but for ambient temperature, the graph show slightly increased. The ambient temperature increased gradually as the chamber was pressure up to the requirement pressure. 
A relation between ambient temperature and pressure is shown in Figure 3. It's significantly fluctuated and unstable due to heating and pressure distribution inside the chamber and also cooling reaction between air and block temperature. The block is cooled and system will overcome it by heat up the block so that it would maintain at certain temperature.

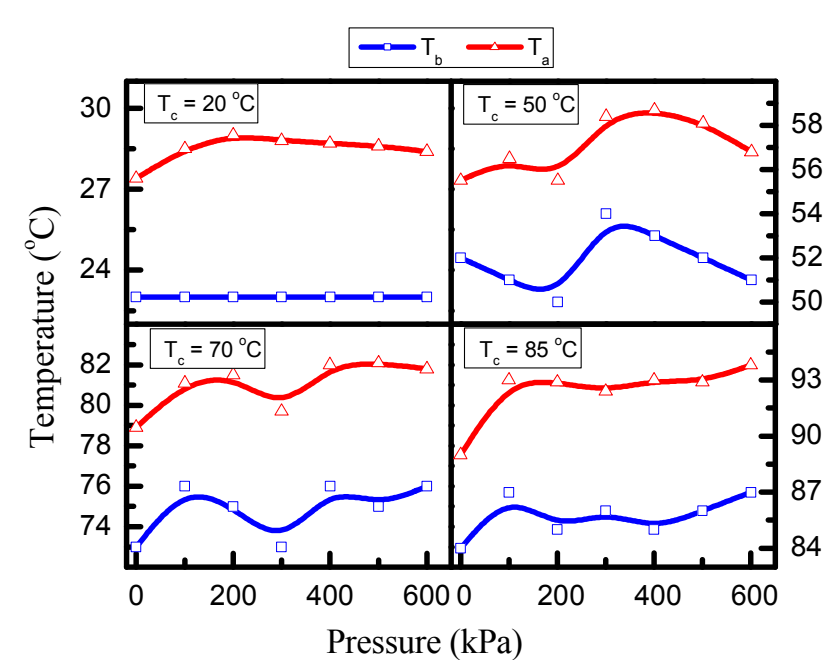

Figure 2 : Effect of Block Temperature on Ambient Temperature

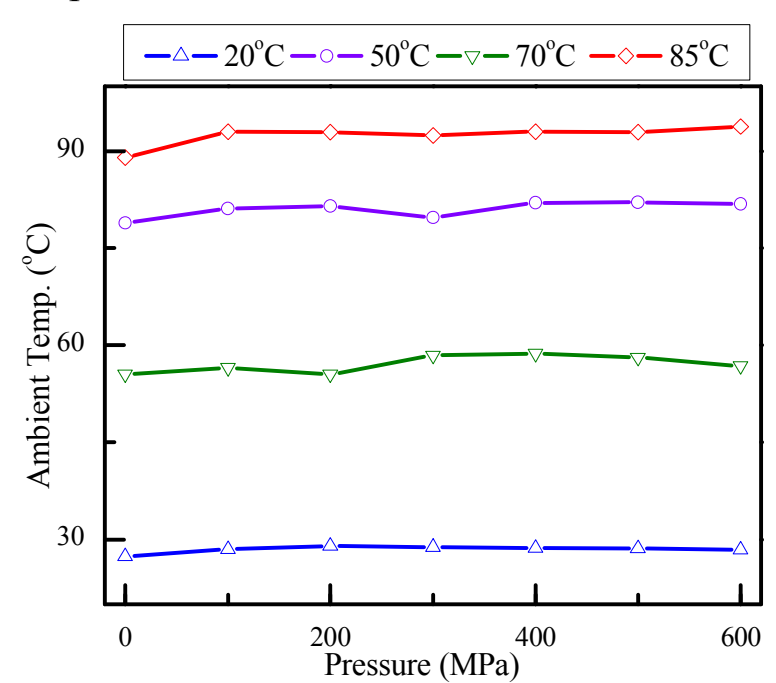

Figure 3 : Relation Between Ambient Temperature and Pressure

The effect of temperature and pressure on the image of spray formation can be studied by injection of diesel fuel into the combustion chamberas shown in Figure 4. The fuel was injected under the block temperature and pressure of the chamber is varied. The internal part of the chamber was black painted, to increase the image contrast and enhance the visibility of the spray. The illumination was directed only towards the spray tip to preserve the image quality of the investigated region. From the figure, it can be seen that the spray pattern of ambient temperature and pressure is the narrowest compared to rest of the spray pattern. The contours of the spray are almost symmetric.The edges of the spray the concentration jumps in a relatively thin layer and that the measurements are only slightly influenced by the illumination[6]. As the temperature and pressure is increased, a great variation in the spray structure is observed. It promotes mixture formation and distributes larger amount of fuel between sprays thus creates good spray atomization and exhibits a greater amount of fuel-air premixing prepared for combustion. Increment of the ambient temperature promotes the evaporation process or on the other hand, evaporation process is elevated by higher ambient temperature [7]. Increases in the ambient temperature causes the rate of fuel evaporation increased. Fuel droplets with small diameter tend to evaporate easily while those with greater diameter take a much longer time to evaporate[8].

The spray area can be employed to represent the mixture formation behavior thus influences the mechanism of fuel-air premixing. When controller temperature, $T_{c}$ is increased, ambient temperature, $\mathrm{T}_{\mathrm{a}}$ increases and it will cause the spray area of diesel inside the chamber increased. Figure 4 presents spray area and spray angle versus pressure for ambient temperatures, $\mathrm{T}_{\mathrm{a}}$ of $20^{\circ} \mathrm{C}$ to $85^{\circ} \mathrm{C}$ for a better visual comparison.

Spray angle is a very important parameter in a compression ignition engine such as the diesel engine. Spray angle are also referred as cone angle that is formed from the exit orifice of spray nozzle. The spray cone angle reflects directly the atomization and air entrainment processes downstream the nozzle hole. Hence, it will be closely linked to the global spray behavior and particularly to its penetration [9]. Figure 5 illustrate the spray angle results under different ambient temperature with pressure. The spray angle increases with respect to the increase in temperature. Spray angle increases obviously due to effect of ambient temperature on fuel atomization[3]. However, when the ambient temperature is over $70^{\circ} \mathrm{C}$, the ambient temperature level has no apparent effect on spray angle. 


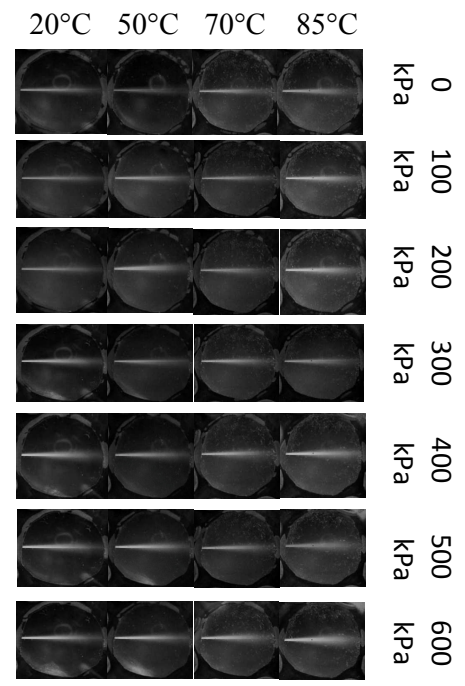

Figure 4: The Effect of Variant Temperature and Pressure on Images of Spray Pattern

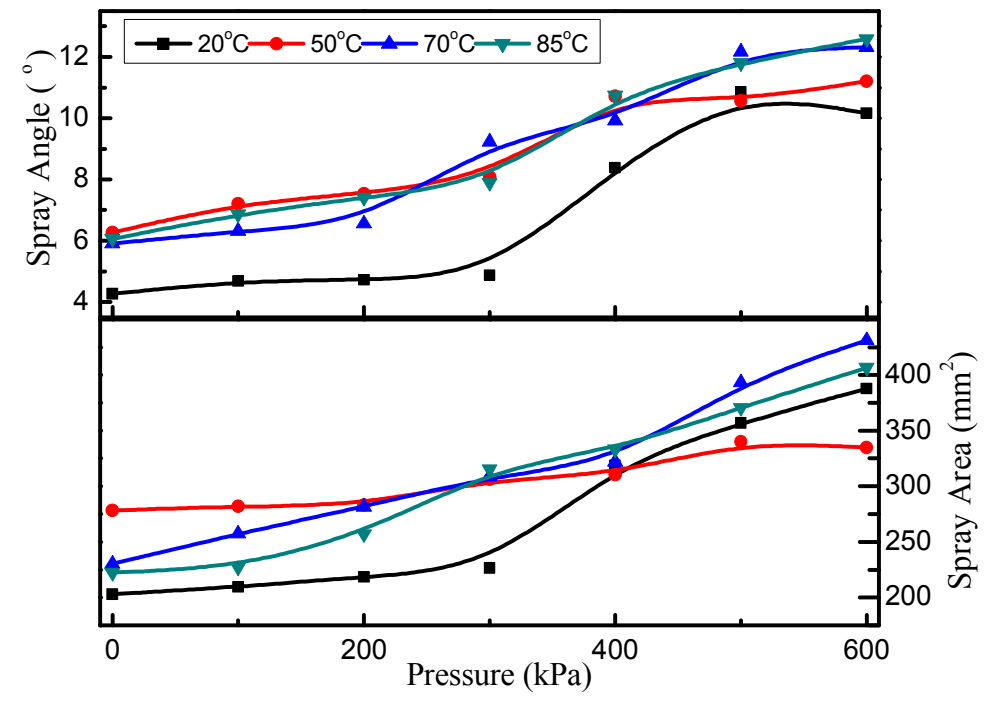

Figure 5: Effect of Pressure on Spray Angle and Spray Area

Figure 6 presents penetration length, spray angle and spray area versus time for all ambient pressures. When the injection quantity is constant, the penetration length is higher at a pressure of 1 Mpa. This is might be because fuel evaporation is delayed due to poor atomization at low ambient pressure. But no significant difference was observed in the penetration length at ambient pressure of 0.6 and $0.8 \mathrm{MPa}$. The injector has a shortest penetration length at a pressure of $0.4 \mathrm{MPa}$. Although atomization is accelerated more and spray is vaporized earlier at an ambient pressure of $0.4 \mathrm{Mpa}$ than at $1 \mathrm{Mpa}$, the spray momentum is higher at $0.4 \mathrm{Mpa}$. On the hand, the vapor penetration rate became higher as the ambient pressure was decreased, possibly because the spray momentum decreases with an increase in the ambient temperature.

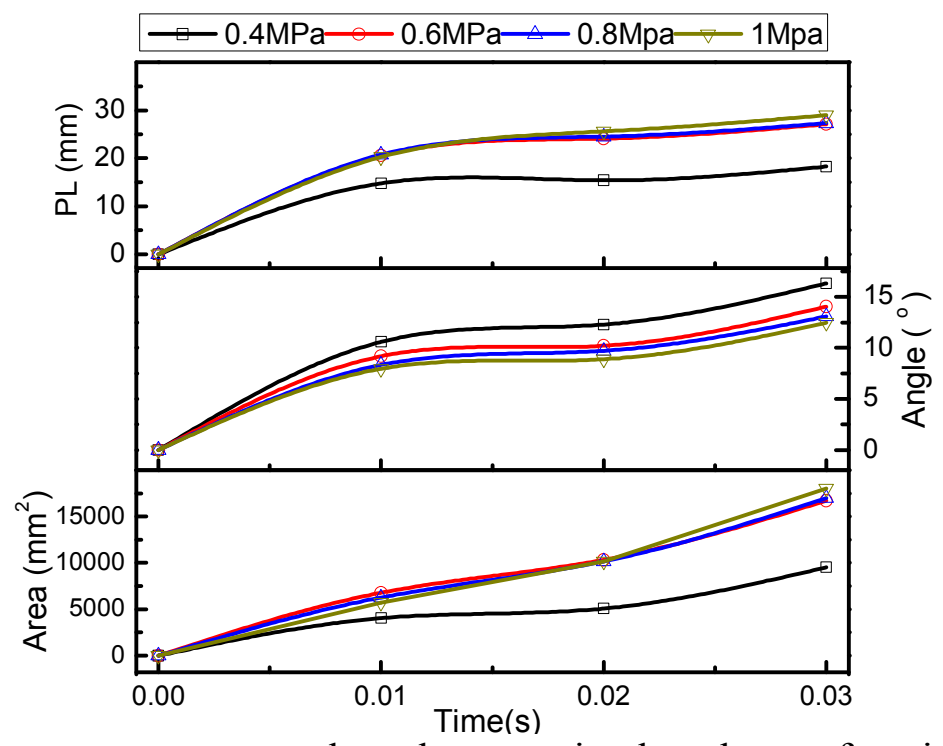

Figure 6: Spray area, spray angle and penetration length, as a function of time at various ambient temperatures.

The spray angle initially increases with time and tends to take a constant value. The spray angle widened as the ambient pressure became lower. In an early stage of injection, $0.01 \mathrm{~ms}$ after start of injection, where diffusion is yet to advance, differences in spray angle between ambient pressures are small. It is estimated that a high ambient pressure leads to loss of spray momentum at an early stage after injection, with the spray spreading horizontally, and that the spray diffuses insufficiently with the fuel evaporated earlier continuing to drift around the spray. 
The projected spray area can be employed to represent the quality of fuel air mixing [10]. It can be observed that spray area increases with pressure but seems to reach a limit whereas the spray area did not further increasing when the injection pressure is increased at 80 and $100 \mathrm{Mpa}$. This is because the penetration length did not increased with pressures injector at certain point due to vapor formation. Liquid phase fuel penetration is one of the important factors to optimize combustion process. The distribution of the fuel in such way of the diesel fuel can be atomized,vaporized and mixed with air effectively in space in short time. Penetration of the liquid phase fuel is necessary to promote fuel air mixing.

\section{Conclusion}

The results obtained in this study are summarized as follows:

1. Increasing block temperature is directly proportional to the ambient temperature inside the chamber at low pressure.

2. The trend of decrease in ambient temperature could be seen even though the block temperature continues increased.

3. As temperature of chamber is increased, the spray angle widens whereas the area of spray becomes larger.

4. Increase of pressure in the chamber creates smaller spray angle due to loss of momentum at an early stage of injection.

\section{Acknowledgements}

The authors also would like to thank the Universiti Tun Hussein Onn Malaysia and Ministry of Higher Education, Malaysia for supporting this research under the Fundamental Research Grant Scheme VOT.1054.

\section{References}

[1] O. Abiola, J. Zhu, K. Nishida, X. Wang, and Z. Huang, "Characterization of spray and combustion processes of biodiesel fuel injected by diesel engine common rail system," FUEL, 2012.

[2] Amir Khalid, Keisuke Hayashi, Yoshiyuki Kidoguchi, Tomoaki Yatsufusa, "Effect of air entrainment and oxygen concentration on endothermic and heat recovery process of diesel ignition", (2011) SAE Technical Papers, DOI: 10.4271/2011-01-1834.

[3] Amir Khalid, N.Tamaldin, M. Jaat, M. F. M. Ali, B. Manshoor, Izzuddin Zaman, "Impacts of biodiesel storage duration on fuel properties and emissions", Procedia Engineering, volume 68, 2013, Pages 225 - 230, Elsevier, 2013, DOI: 10.1016/j.proeng.2013.12.172.

[4] Y. Wang, C. Yang, and G. Shu, "An Observation of High Temperature Combustion Phenomenon in Low-Heat- Rejection Diesel Engines," SAE Pap. No 940949, no. 412, 1994.

[5] K. Miwa, T. Ohmija, and T. Nishitani, "A Study of the Ignition Delay of Diesel Fuel Spray Using a Rapid Compression Machine," JSME Int J, Ser II, vol. 31, p. 166, 1988.

[6] I. V Roisman, L. Araneo, and C. Tropea, "Effect of ambient pressure on penetration of a diesel spray," vol. 33, pp. 904-920, 2007.

[7] A. Adam, N. Inukai, Y. Kidoguchi, K. Miwa, and S. Miyashiro, "A Study on Droplets Evaporation at Diesel Spray Boundary During Ignition Delay Period." 2007.

[8] M. Jaat, Amir Khalid, B. Manshoor, S.M Basharie, Him Ramsy, "Review of the Investigation of Fuel-Air Premixing and Combustion Process using Rapid Compression Machine and Direct Visualization System", Applied Mechanics and Materials Vols. 465-466 (2014), Trans Tech Publications, Switzerland, pp 265-299.

[9] J. Arrègle, J. V Pastor, and S. Ruiz, "The Influence of Injection Parameters on Diesel Spray Characteristics," SAE Pap. No. 1999-01-0200, 1999.

[10] X. Wang, Z. Huang, O. A. Kuti, W. Zhang, and K. Nishida, "Experimental and analytical study on biodiesel and diesel spray characteristics under ultra-high injection pressure," Int. J. Heat Fluid Flow, vol. 31, no. 4, pp. 659-666, Aug. 2010. 